\title{
The Process of Human Behavior in Fires
}

\author{
Erica D. Kuligowski
}

N15 National Institute of Standards and Technology - U.S. Department of Commerce
QC
100
45753
*1632
2009
c. 2 


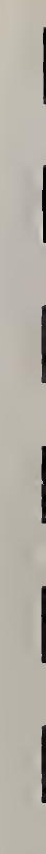


NIST Technical Note 1632

\section{The Process of Human Behavior in Fires}

Erica D. Kuligowski

Fire Research Division

Building and Fire Research Laboratory

May 2009

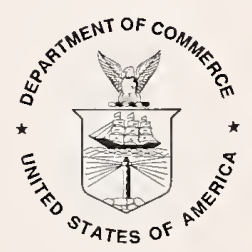

U.S. Department of Commerce Gary Locke, Secretary 
Certain commercial entities, equipment, or materials may be identified in this document in order to describe an experimental procedure or concept adequately. Such identification is not intended to imply recommendation or endorsement by the National Institute of Standards and Technology, nor is it intended to imply that the entities, materials, or equipment are necessarily the best available for the purpose.

National Institute of Standards and Technology Technical Note 1632

Natl. Inst. Stand. Technol. Tech. Note 1632, 15 pages (May 2009)

CODEN: NSPUE2 


\section{Acknowledgements}

Thanks to Kathleen Tierney, Liam Downey, William Grosshandler, Dennis Mileti, and Ross Corotis for their efforts. My appreciation to Richard Peacock, Jason Averill, Anthony Hamins, and Steve Gwynne for providing detailed and insightful suggestions. 


\title{
THE PROCESS OF HUMAN BEHAVIOR IN FIRES
}

\author{
Erica Kuligowski \\ National Institute of Standards and Technology
}

\section{INTRODUCTION}

Evacuation models, including engineering hand calculations and computational tools, are used to calculate the time it takes to evacuate a building, which can then be used in an engineering safety analysis. However, there is a lack of available data and theory on occupant behavior for use by evacuation models to estimate evacuation time results and their uncertainty. In lieu of data and theory, evacuation models (and users) make assumptions and simplifications about occupant behavior, which can inappropriately characterize the time it actually takes to evacuate a building. In cases where assumptions lead to evacuation estimates that are either too optimistic or too conservative, buildings and procedures can be designed with either insufficient or unnecessary (and costly) egress routes and fire protection/notification systems. A solution to this problem is to generate theory on human behavior during evacuations from building fires that can be incorporated into evacuation models. Once this theory is robust, validated and incorporated into evacuation models, these tools can begin to predict occupant evacuation behavior rather than relying on the user to determine behavior before the simulation begins, as is now the case.

In order to develop predictive theory of human behavior in fires, the factors that influence an occupant to take certain actions must be identified. Examples of actions taken during an evacuation include information seeking, milling, preparing for evacuation, and informing others. This paper briefly outlines the factors that influence an occupant to take actions during his/her evacuation and identifies future areas of research that are needed to develop a predictive behavioral (action-based) model of an evacuation during a building fire.

\section{THEORY OF OCCUPANT BEHAVIOR DURING BUILDING FIRES}

Human behavior research has shown that any action performed in a situation is the result of a behavioral or decision-making process, ${ }^{1}$ rather than based on random chance or even actions resulting directly from a change in the environment (i.e., a stimulus-response relationship). Research from community evacuations during disasters ${ }^{2,3,4}$ and building fire evacuations ${ }^{5,6,7,8,9}$ has shown that before individuals performed an action, they perceived certain cues, interpreted the situation and the risk based on those cues, and then made a decision about what to do (i.e., the action) based on their interpretations. Therefore, each action taken is influenced by this process. Also, there are certain factors that influence each phase of the process; more specifically 1) factors that influence whether the individual perceives the cue (or not), 2) factors that influence what type of interpretation the individual forms about the situation and the risk based on that cue, and 3) factors that influence the decision about an action. This behavioral process is shown in Figure 1. 


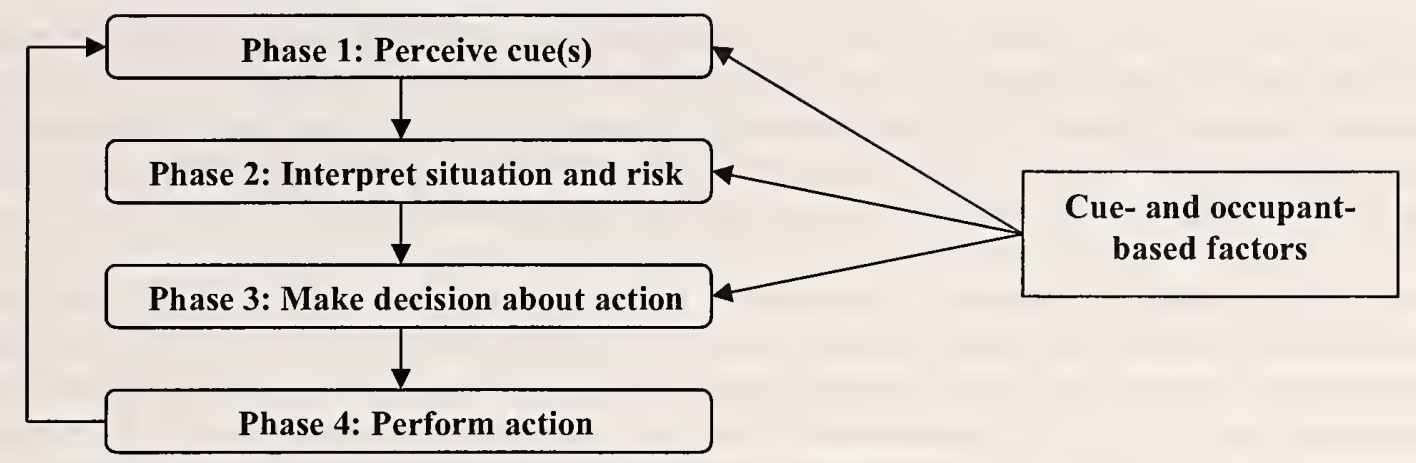

Figure 1: The behavioral process of occupant response in a building fire

In a building fire, the phases and the factors that influence each action are specific to the occupants in the building, the building itself, and the fire event. In the perception phase (Phase 1) of the behavioral process from Figure 1, building occupants can perceive (or receive) external physical and social cues from their environment, including such physical cues as flames, smoke, heat, or debris and such social cues as hearing discussion, seeing others' inaction, or receiving phone calls from outside of the building. Additionally, during this phase, occupants can perceive more complex conditions and states, such as perceived uncertainty, information overload, time pressure, and even their own thoughts or memories from a particular event. In the interpretation phase, Phase 2, the occupant attempts to interpret the information provided by the cues perceived during the perception phase. ${ }^{10,11,12}$ During the interpretation phase, occupants interpret or define both the situation (e.g., it is a false alarm or a very serious fire) and the risk to themselves and/or to others. Phase 3 of the behavioral process, decision-making, involves occupants making decisions on what to do next based on their interpretations of the situations and risks. ${ }^{13,14}$ And, finally, in Phase 4 of the behavioral process, occupants may perform the action that they decided upon in the decision-making phase. For a more complete version of the theory behind each phase in the process, see reference [15].

Occupants will begin a behavioral process when presented with cues or information that interrupts their daily routine. A new behavioral process begins each time an occupant receives new information relating to the event, and a specific action is likely to occur based on whether the information is perceived, the interpretation of the situation and the risk, and the decisions made regarding what to do.

\section{CONCEPTUAL MODEL FOR EVACUATION BEHAVIOR IN BUILDING FIRES}

To eventually develop a predictive behavioral model, an understanding of the factors that influence each phase of the behavioral process for building fires is required. Literature from community disasters and building fire evacuations were collected and reviewed to identify these factors. This is a difficult task for several reasons. First, there are both direct and indirect factors that influence each phase of the behavioral process. Direct factors actually influence the main process in each phase, whereas indirect factors can influence the subprocesses that take place within each phase. Second, whereas the perception phase contains a small number of alternatives (i.e., either an individual perceives the cue or not), the interpretation, decision-making and action phases have a large number of options which makes it very difficult to develop linkages between these phases. When presented with building fire cues, for example, occupants have a large number of interpretations that can be made regarding the situation and the risk (Phase 2). Additionally, occupants can perform a large number of actions (Phases 3 and 4). Whereas, if the occupant perceives a cue(s), then he/she will begin to engage in interpretation, few studies ${ }^{16}$ were found that effectively linked specific interpretations (Phase 2) with decisions made about specific actions to perform (Phase 3). 
This paper begins the development of a predictive behavioral model by identifying the direct factors of influence for Phases 1 and 2 (perception and interpretation). The focus of this paper is to present the factors that influence 1) whether a cue is perceived, 2) whether an occupant interprets the situation as a fire, and 3) whether the occupant interprets a level of risk. In addition, the direction of influence is also included (e.g., whether a factor increases or decreases the likelihood of the phase).

The factors of influence for Phases 1 and 2 have been categorized into two main types: occupant-based factors and cue-based factors. Occupant-based factors include pre-event factors which are those factors possessed by the occupant prior to an event taking place, i.e., education, training, demographic characteristics, etc.; event factors are possessed by the occupant as a function of the event. Cue-based factors, which are inherently event factors, vary by the number of cues, the complexity of the cues (e.g., ambiguous, inconsistent, and too many in number), and the source or type of cue (e.g., smoke condition, other occupants in the building, and people's actions).

Table 1 provides an overview of the influential factors for Phases 1 and 2 of the behavioral process and their direction of influence based on data and theory from human behavior in fires, community-wide disasters, and other types of emergencies. The table should be read in the following way: If [insert factor here], then the likelihood of 1) perceiving a cue, 2) defining the situation as a fire, or 3) defining the risk to self and/or others [insert direction of influence here - i.e., Increases or Decreases]. An example of this using the factor "Has a perceptual disability (Yes)" is the following: If an occupant has a perceptual disability, then the likelihood of perceiving a cue decreases. A full list of references is provided for each relationship described in Table 1 in the following text.

Table 1: An overview of influential factors for Phases 1 and 2 of the behavioral process

\begin{tabular}{|c|c|c|c|}
\hline \multirow[b]{2}{*}{ Factors } & \multirow{2}{*}{$\begin{array}{c}\text { Phase 1 } \\
\text { Perception }\end{array}$} & \multicolumn{2}{|c|}{ Phase 2: Interpretation } \\
\hline & & $\begin{array}{l}\text { 2a: Definition of the } \\
\text { Situation as a Fire }\end{array}$ & $\begin{array}{l}\text { 2b: Definition of the } \\
\text { Risk to Self/Others }\end{array}$ \\
\hline \multicolumn{4}{|l|}{ Occupant-based pre-event factors } \\
\hline Has experience with fires (Yes) & Increases & Increases & Increases \\
\hline Has knowledge of fire/training (Yes) & Increases & Increases & Increases \\
\hline Habituation with environment (Yes) & Decreases & ---* & --- \\
\hline Has knowledge of routes (Yes) & --- & -- & Decreases \\
\hline Has frequent experience with "false" alarms (Yes) & --- & Decreases & -- \\
\hline Has a feeling of security in building (Yes) & --- & Decreases & --- \\
\hline Has a perceptual disability (Yes) & Decreases & --- & --- \\
\hline Age (Older adults) & Decreases & --- & Increases \\
\hline Gender (Woman) & Increases & -- & Increases \\
\hline Speaks the same language as others (Yes) & Increases & -- & --- \\
\hline Has frequent interaction with family (Yes) & Increases & --- & --- \\
\hline \multicolumn{4}{|l|}{ Occupant-based event factors } \\
\hline Has a higher stress/anxiety level & Decreases & --- & --- \\
\hline Perceives a time pressure (Yes) & Decreases & Decreases & lncreases \\
\hline Presence of others (especially loved ones) (Yes) & Decreases & --- & Increases \\
\hline Proximity to fire/Visual access (Yes) & Increases & --- & --- \\
\hline Sleeping (Yes) & Decreases & -- & $\cdots$ \\
\hline A higher number of behavioral processes $(>I)$ & --- & Increases & -- \\
\hline Defines situation as fire (Yes) & -- & N/A & Increases \\
\hline \multicolumn{4}{|l|}{ Cue-based factors } \\
\hline A higher number of cues & Mixed** & Increases & Increases \\
\hline Consistent cues (Yes) & --- & lncreases & Increases \\
\hline Unambiguous cues (Yes) & -- & Increases & --- \\
\hline $\begin{array}{l}\text { Social cues (others' actions) that are consistent with an } \\
\text { understanding of a fire situation (Yes) }\end{array}$ & -- & Increases & Increases \\
\hline Official source (Yes) & lncreases & Increases & -- \\
\hline Familiar source (Yes) & -- & Increases & --- \\
\hline A higher dose of toxic gases & --- & Decreases & --- \\
\hline Extreme/dense cues (Yes) & Decreases & --- & lncreases \\
\hline Visual/audible cues (Yes) & Increases & --- & --- \\
\hline Risk information (Yes) & --- & Increases & --- \\
\hline
\end{tabular}

*Areas where no research was found is marked by "--."; **Research conflicted on the direction of influence of the factor. 


\section{Phase 1: Perception}

In Table 1, research shows that both occupant- and cue-based factors influence whether a person perceives a cue. Mileti and Sorensen provide a compilation of all of the factors that influence whether community residents will hear a warning, many of which apply to building fires. The occupant-based preevent factors that are shown to increase the likelihood of perception are having prior experience with disasters and fires, ${ }^{17,18,19,20}$ having some type of knowledge and/or training about fires, ${ }^{21}$ being a woman, ${ }^{22}$ speaking the same language as the message and others in the building, ${ }^{23}$ and having frequent interaction with family.", ${ }^{24,25}$ On the other hand, the occupant-based pre-event factors that are shown to decrease the likelihood of perception are past experience/habituation with the environment (i.e., spending extended hours in the same environment where the event takes place), ${ }^{26,27,28,29}$ having a perceptual disability (i.e., a cognitive disability or even loss of any of the senses), ${ }^{30,31}$ and being older (i.e., older adults).",32,33,34,35,36,37

There are also occupant-based event factors that influence perception. The factors that increase the likelihood of perception are being located closer to the event",38,39,40,41,42 and having visual access of the event, ${ }^{43,44,45}$ whereas those factors that decrease the probability of an occupant perceiving a cue include having higher levels of stress or anxiety, ${ }^{46,47}$ perceiving time pressure, the presence of others on the floor or in the area, and being asleep"..,48,49 (especially if he/she is very young or very old, ${ }^{50}$ intoxicated, ${ }^{51}$ sleep deprived, or in a deep stage of sleep ${ }^{52}$ ).

Last, research shows that there are cue-based factors that influence whether a person perceives a cue. The cue-based factors that increase the probability of perception include cues from the fire event that are easy to hear (audible),"'” cues that are presented by an official source (e.g., staff, fire warden, etc.),"53,54,55 and a higher number of cues;"', although if the occupant receives too many cues at the same time, this actually decreases the likelihood of perceiving the cue (i.e., this is the reason a label of "Mixed" is assigned to this category in Table 1). The factor that is shown to decrease the likelihood of perception is the presence of thick, dense smoke ${ }^{56,57,58,59,60}$ that prohibits the occupant from seeing the space around him/her (labeled in Table 1 as "Extreme/dense cues").

\section{Phase 2a: Definition of the situation as a fire}

Occupants can interpret the situation in many ways; however, the factors that are listed in Table 1 identify those factors that influence whether an occupant interprets a building fire event as a fire event (rather than a false alarm, an evacuation drill, etc.). The occupant-based pre-event factors that increase the likelihood of the occupant defining the situation as a fire are having past experience with fires and having knowledge or training on what to do during fire events."”,61,62,63,64,65,66 On the other hand, an occupant with frequent false alarm experience' or who feels secure/safe in their building, ${ }^{1.67,68}$ is less likely to accurately define the situation as a fire.

Additionally, occupant-based event factors influence whether an occupant defines the situation as a fire. First, research suggests that time pressure negatively affects the development and accuracy of an occupant's definition of the event. Also, research shows that if the occupant is engaging in his/her first behavioral process during the evacuation (resulting in his/her first action), he/she is less likely to define the situation as a fire, and additionally, is more likely to define the situation optimistically. In other words, people's first inclination is to think that nothing bad is happening to them and that they do not need to act. ${ }^{69,70}$

Table 1 also shows that there are many cue-based factors that influence whether an occupant will interpret the situation as a fire. The occupant's definition of the situation as a fire is more likely when the occupant is presented with a higher number of cues, ${ }^{, 71,72}$ a consistent set of cues (e.g., the smoke, flames, heat, and 
debris all lead to the same interpretation), ${ }^{73,74,75}$ and unambiguous cues."'‥, 76 Other factors that increase the likelihood of the occupant interpreting the situation as a fire include perceiving social cues that are consistent with an understanding of a fire situation (e.g., hearing screams, seeing others act, etc.),"77,78 cues from official sources (e.g., the fire department),"”,79,80,81,82 cues from familiar sources (e.g., friends, family, etc.), ${ }^{83}$ and cues that provide risk information as part of the warning message ${ }^{84}$ On the other hand, if occupants are exposed to certain environmental cues, such as toxic gases from smoke for a certain period of time (e.g., $\mathrm{CO}, \mathrm{HCN}$, low $\mathrm{O}_{2}$ ), this exposure itself is likely to negatively affect his/her cognitive abilities, including the ability to construct an accurate definition of the situation.. ${ }^{85,86,87}$ Prolonged exposure may lead to incapacitation or death.

\section{Phase 2b: Definition of the risk to self/others}

The occupant-based pre-event factors that increase the likelihood of an occupant defining risk include having past experiences with fires and/or knowledge/training for fires,"'” being older (e.g., older adults), and being a woman. ${ }^{88}$ On the other hand, one study shows that having knowledge of the evacuation routes from a building can decrease the likelihood of an occupant interpreting risk. Also, research identifies three occupant-based event factors that increase the likelihood of an occupant defining risk, and those factors are time pressure (or feeling a sense of urgency), ${ }^{89}$ the presence of loved ones within the building (e.g. friends, family, etc.), ${ }^{90}$ and if the occupant has already defined the situation as a fire, ${ }^{, 11}$ it is more likely that he/she will feel risk to him/herself or to others.

Last, cue-based factors also influence an occupant's perception of risk. A higher number of cues, ${ }^{92,93}$ a consistent set of cues, ${ }^{94}$ the presence of social cues that are consistent with an understanding of a fire situation, ${ }^{95,96}$ and the presence of more extreme cues (e.g., dense smoke), ${ }^{97}$ increase the likelihood of an occupant defining risk to him/herself or others.

\section{CONCLUSION}

Behavior during a building fire evacuation is the result of a behavioral process. Each process begins with new cues and information from the physical and social environment. First, cues need to be perceived, then they are interpreted, and then a decision is made as to what action (including inaction) is undertaken. During an evacuation, individuals repeat this process several times as they engage in a variety of different activities. This paper presents the influential factors for the perception phase and a subset of the interpretation phase of the behavioral process, however, future research, in the form of an in-depth study of real fire events, is needed to identify the factors that influence occupants to decide to take a specific action, and the factors that influence whether that action is ultimately performed. By identifying the factors that have been shown to influence each phase in the behavioral process, researchers can begin to develop a comprehensive, predictive, behavioral model for a building fire evacuation.

\section{REFERENCES:}

${ }^{1}$ Blumer, Herbert. 1969. Symbolic Interactionism: Perspective and Method. Berkley, CA: University of California Press.

${ }^{2}$ Mileti, Dennis S. and John H. Sorensen. 1990. "Communication of Emergency Public Warnings: A Social Science Perspective and State-of-the-Art Assessment." Oak Ridge, TN: Oak Ridge National Laboratory, U.S. Department of Energy.

${ }^{3}$ Perry, Ronald W., Michael K. Lindell, and Marjorie R. Greene. 1981. Evacuation Planning in Emergency Management. Lexington, MA: Lexington Books. 
${ }^{4}$ Mileti, Dennis S. and E. M. Beck. 1975. "Communication in Crisis: Explaining Evacuation Symbolically." Communication Research 2(1):24-49.

${ }^{5}$ Bryan, John L. 2002. "Behavioral Response to Fire and Smoke." Pp. 3-315 - 3-341 in The SFPE Handbook of Fire Protection Engineering Third Edition, edited by P.J. DiNenno. Quincy, MA: National Fire Protection Association.

${ }^{6}$ Feinberg, W. E. and Norris R. Johnson. 1995. "Firescap: A Computer Simulation Model of Reaction to a Fire Alarm." Journal of Mathematical Sociology 20:247-269.

${ }^{7}$ Tong, D. and David Canter. 1985. "The Decision to Evacuate: A Study of the Motivations which Contribute to Evacuation in the Event of a Fire." Fire Safety Journal 9:257-265.

${ }^{8}$ Edelman, P., E. Herz, and L. Bickman. 1980. "A Model of Behaviour in Fires Applied to a Nursing Home Fire." Pp. 181-203 in Fires and Human Behaviour, edited by D. Canter. New York, NY: John Wiley \& Sons.

${ }^{9}$ Breaux, J., David Canter, and Jonathan D. Sime. 1976. "Psychological Aspects of Behaviour of People in Fire Situations." Pp. 39-50 in International Fire Protection Seminar, $5^{\text {th }}$. Karlsruhe, West Germany.

${ }^{10}$ Weick, Karl E. 1995. Sensemaking in Organizations. Thousand Oaks, CA: Sage Publications.

${ }^{11}$ Canter, David, Ian Donald, and Judith Chalk. 1992. "Pedestrian Behaviour during Emergencies Underground: The psychology of crowd control under life threatening circumstances." Pp. 135-150 in Safety in Road and Rail Tunnels, edited by A. Vardy. Bedford: Independent Technical Conferences Ltd.

${ }^{12}$ Turner, Ralph H. and Lewis M. Killian. 1987. Collective Behavior. Englewood Cliffs, NJ: Prentice Hall, Inc.

${ }^{13}$ Gigerenzer, G. and R. Selten. 2001. Bounded Rationality: The Adaptive Toolbox. Cambridge, MA: The MIT Press.

${ }^{14}$ Simon, H. A. 1956. "Rational Choice and the Structure of Environments." Psych. Rev. 63:129-138.

${ }^{15}$ Kuligowski, Erica D. 2008. "Modeling Human Behavior during Building Fires." NIST Technical Note 1619. Gaithersburg, MD: National Institute of Standards and Technology.

${ }^{16}$ Fahy, RF \& Proulx, G 1997, 'Human behavior in the World Trade Center evacuation' Fire Safety Science -Proceedings of the Fifth International Symposium, The International Association for Fire Safety Science, London, England, pp. 713-724.

${ }^{17}$ Blanchard-Boehm, R. Denise. 1998. "Understanding Public Response to Increased Risk from Natural Hazards: Application of the Hazards Risk Communication Framework." International Journal of Mass Emergencies and Disasters 16:247-278.

${ }^{18}$ Perry, Ronald W. and Michael K. Lindell. 1986. "Twentieth-Century Volcanicity at Mt. St. Helens: The Routinization of Life Near an Active Volcano." Tempe, AZ: School of Public Affairs, Arizona State University.

${ }^{19}$ Lardry, Thomas and George Rogers. 1982. Warning Confirmation and Dissemination. Pittsburgh: Center for Social and Urban Research, University of Pittsburgh.

${ }^{20}$ Turner, Ralph H., Joanne M. Nigg, Denise H. Paz, and Barbara S. Young. 1981. "Community Response to Earthquake Threat in Southern California, Part 10, Summary and Recommendations." Los Angeles, CA: Institute for Social Science Research, University of California, Los Angeles.

${ }^{21}$ Klein, Gary. 1999. Sources of Power: How People Make Decisions. Cambridge, MA: The MIT Press. 
${ }^{22}$ Turner, Ralph H., Joanne M. Nigg, Denise H. Paz, and Barbara S. Young. 1979. "Earthquake Threat: The Human Response in Southern California." Los Angeles, CA: Institute for Social Science Research, University of California, Los Angeles.

${ }^{23}$ Aguirre, Benigno E., Walter A. Anderson, Sam Balandran, Brian E. Peters, and H. Max White. 1991. Saragosa, Texas, Tornado, May 22, 1987: An Evaluation of the Warning System. Washington, D.C.: National Academy Press.

${ }^{24}$ Perry, Ronald W. and Majorie R. Greene. 1982. "The Role of Ethnicity in the Emergency Decision-Making Process." Sociological Inquiry 52:309-334.

${ }^{25}$ Perry, Ronald W. 1979. "Evacuation Decision-Making in Natural Disasters.” Mass Emergencies 4:25-38.

${ }^{26}$ Bruck, Dorothy. 2001. "The who, what, where and why of waking to fire alarms: A review." Fire Safety Journal 36:623-639.

${ }^{27}$ Plous, Scott. 1993. The Psychology of Judgment and Decision Making. Philadelphia, PA: Temple University Press.

${ }^{28}$ Ramey-Smith, A. M. and J. V. Fechter. 1979. "Group Homes for the Developmentally Disabled: Case Histories of Demograhics, Household Activities, and Room Use." NBS Report No. NBSIR 791727. Washington, DC: National Bureau of Standards.

${ }^{29}$ Latane, Bibb and John M. Darley. 1970. The Unresponsive Bystander: Why doesn't he help? New York, NY: Appleton-Century Crofts.

${ }^{30}$ Bruck, Dorothy and Ian Thomas. 2007. Waking effectiveness of alarms (auditory, visual and tactile) for adults who are hard of hearing. Quincy, MA: The Fire Protection Research Foundation.

${ }^{31}$ Proulx, Guylene. 1995. "Evacuation Time and Movement in Apartment Buildings." Fire Safety Journal 24:229246.

${ }^{32}$ Proulx, G., I. M. A. Reid and N. R. Cavan. 2004. Human Behavior Study, Cook County Administration Building Fire, October 17, 2003 - Chicago, IL. Ottawa, Canada: National Research Council of Canada.

${ }^{33}$ Brennan, Patricia. 1997. "Timing Response in Real Fires." Pp. 807-818 in Fire Safety Science - Proceedings of the Fifth International Symposium. London, England: Interscience Communications Ltd.

${ }^{34}$ Proulx, Guylene and Joelle Pineau. 1996. "The Impact of Age on Occupants' Behaviour During a Residential Fire." Human Factors and Ergonomics Society $40^{\text {th }}$ Annual Meeting. Santa Monica, CA: Human Factors and Ergonomics Society.

${ }^{35}$ Rogers, George O. 1985. "Some Policy Implications of Human Components of Emergency Warning." Pittsburgh, PA: Center for Social and Urban Research, University of Pittsburgh.

${ }^{36}$ Turner, Ralph H. 1976. "Earthquake Prediction and Public Policy: Distillations from a National Academy of Sciences Report." Mass Emergencies 1:179-202.

${ }^{37}$ Mileti, Dennis S. 1975. "Natural Hazard Warning Systems in the United States: A Research Assessment." Program on Technology, Environment and Man, Boulder, CO: Institute of Behavioral Sciences, University of Colorado.

${ }^{38}$ Donald, I. and D. Canter. 1990. "Behavioural Aspects of the King's Cross Disaster." Pp. 15-30 in Fires and Human Behaviour, edited by D. Canter. New York, NY: John Wiley and Sons. 
${ }^{39}$ Lerup, L. D. Conrath, and J. K. C. Liu. 1980. "Fires in Nursing Facilities." Pp. 155-180 in Fires and Human Behaviour, edited by D. Canter. New York, NY: John Wiley and Sons.

${ }^{40}$ Bryan, John L. 1977. Smoke as a Determinant of Human Behavior in Fire Situations. College Park, MD: University of Maryland, College Park.

${ }^{41}$ Mileti, Dennis S., Thomas E. Drabek, and J. Eugene Haas. 1975. Human Systems in Extreme Environments: A Sociological Perspective. Boulder, CO: Institute of Behavioral Science, University of Colorado.

${ }^{42}$ Diggory, James C. 1956. "Some Consequences of Proximity to a Disease Threat." Sociometry 19:47-53.

${ }^{43}$ Proulx, Guylene. 2000. "Occupant Response to Fire Alarm Signals." NFPA 72 Fire Alarm Code, Supplement 4. Quincy, MA: National Fire Protection Association.

${ }^{44}$ Sime, Jonathan D. 1998. "Visual Access Configurations: Spatial Analysis and Occupant Response Inputs to Architectural Design and Fire Engineering." P. 140-151 in Proceedings of the $15^{\text {th }}$ International Association for People-Environment Studies Conference,.

${ }^{45}$ Proulx, Guylene and Rita F. Fahy. 1997. "Time Delay to Start Evacuation: Review of Five Case Studies." Pp. 783-806 in Fire Safety Science - Proceedings of the Fifth International Symposium. London, England: Interscience Communications Ltd.

${ }^{46}$ Baumann, Michael R., Janet A. Sniezek, and Clayton A. Buerkle. 2001. "Self-Evaluation, Stress, and Performance: A Model of Decision Making Under Acute Stress." Pp. 139-158 in Linking Expertise and Naturalistic Decision Making, edited by E. Salas and G. Klein. Mahwah, NJ: Lawrence Erlbaum Associates, Inc.

${ }^{47}$ Ozel, F. 1998. "The Role of Time Pressure and Stress on the Decision Process during Fire Emergencies." Pp. 191200 in Proceedings of the First International Symposium on Human Behavior in Fire, edited by T. J. Shields. London, England: Interscience Communications Ltd.

${ }^{48}$ Brennan, Patricia. 1999. "Modelling Cue Recognition and Pre-Evacuation Response." Pp. 1029-1040 in Proceedings $-6^{\text {th }}$ International Symposium, International Symposium. London, England: International Association for Fire Safety Science.

${ }^{49}$ Lynch, J. 1998. "Nocturnal Olfactory Response to Smoke Odor." Pp. 231-242 in $I^{\text {st }}$ International Symposium of Human Behaviour in Fire, edited by T. J. Shields. London, England: Interscience Communications Ltd.

${ }^{50}$ Bruck, Dorothy. 1997. "Arousal from Sleep with a Smoke Detector Alarm in Children and Adults." Melbourne, Australia: Department of Psychology, Victoria University of Technology.

${ }^{51}$ Nober, E. H., H. Peirce, and A. D. Well. 1981. "Acoustic spectral characteristics of household smoke detector alarms." Fire Journal May: 94-98 (+144).

${ }^{52}$ Pezoldt, V. J. and H. P. Van Cott. 1978. "Arousal from Sleep by Emergency Alarms: Implications from the Scientific Literature. NBS Report No. NBSIR-78-1484. Washington, DC: National Bureau of Standards.

${ }^{53}$ Mileti, Dennis S. and JoAnne DeRouen Darlington. 1995. "Societal Response to Revised Earthquake Probabilities in the San Francisco Bay Area." International Journal of Mass Emergencies and Disasters 13:119-145.

${ }^{54}$ Rogers, George O. and John H. Sorensen. 1991. "Diffusion of Emergency Warning: Comparing Empirical and Simulation Results." Risk Analysis 11:117-134. 
${ }^{55}$ Lindell, Michael K. and Ronald W. Perry. 1987. "Warning Mechanisms in Emergency Response Systems." International Journal of Mass Emergencies and Disasters 5 (2):137-153.

${ }^{56}$ Purser, David. 2002. "Toxicity Assessment of Combustion Products." Pp. 2-83 - 2-171 in The SFPE Handbook of Fire Protection Engineering Third Edition, edited by P.J. DiNenno. Quincy, MA: National Fire Protection Association.

${ }^{57}$ Jin, T. 1997. "Studies on Human Behavior and Tenability in Fire Smoke." Pp. 3-21 in Fire Safety ScienceProceedings of the Fifth International Symposium, edited by Y. Hasemi. London, England: Interscience Communications Ltd.

${ }^{58}$ Jin, T. and T. Yamada. 1985. "Irritating Effects of Fire Smoke on Visibility." Fire Science and Technology 5:7989.

${ }^{59}$ Jin, T. 1978. "Visibility through Fire Smoke." Journal of Fire and Flammability 9:135-157.

${ }^{60}$ Phillips, A. W. 1978. "The Effects of Smoke on Human Behavior -- A Review of the Literature." Fire Journal 72:69-123.

${ }^{61}$ Hodler, Thomas W. 1982. "Resident's Preparedness and Response to the Kalamazoo Tornado." Disasters 6 (1):44-49.

${ }^{62}$ Sorensen, John H. 1982. "Evaluation of Emergency Warning System at Ft. St. Vrain Nuclear Power Plant." Oak Ridge, TN: Oak Ridge National Laboratory.

${ }^{63}$ Quarantelli, E. L. 1980. "Evacuation Behavior and Problems: Findings and Implications from the Research Literature." Columbus, OH: Disaster Research Center, Ohio State University.

${ }^{64}$ Drabek, Thomas E. and Keith Boggs. 1968. "Families in Disaster: Reactions and Relatives." Journal of Marriage and the Family 30:443-451.

${ }^{65}$ Fritz, Charles E. 1961. "Disasters.” Pp. 651-694 in Contemporary Social Problems, edited by R. K. Merton and R. A. Nisbet. New York, NY: Harcourt.

${ }^{66}$ Mack, R.W. and G.W. Baker. 1961. "The Occasion Instant: The Structure of Social Responses to Unanticipated Air Raid Warnings. National Research Council, Publication 945, Washington, DC: National Academy of Sciences.

${ }^{67}$ Vaughan, Diane. 1999. "The Dark Side of Organizations: Mistake, Misconduct, and Disaster." Annual Review of Sociology 25:271-305.

${ }^{68}$ Vaughan, Diane. 1996. The Challenger Lauch Decision. Chicago, IL: University of Chicago Press.

${ }^{69}$ Drabek, Thomas E. 1969. "Social Processes in Disaster: Family Evacuation.” Social Problems 16:336-349.

${ }^{70}$ Fritz, Charles E. and J.H. Mathewson. 1957. "Convergency Behavior in Disasters." Washington, D.C.: National Research Council, National Academy of Sciences.

${ }^{71}$ Brennan, Patricia. 1996. "Impact of Social Interaction on Time to Begin Evacuation in Office Building Fires: Implications for Modelling Behaviour." Pp. 701-710 in Interflam '96. International Interflam Conference, 7th Proceedings, edited by C. A. Franks and S. Grayson. London, England: Interscience Communications.

${ }^{72}$ Mileti, Dennis S. and E. M. Beck. 1975. "Communication in Crisis: Explaining Evacuation Symbolically." Communication Research 2(1):24-49. 
${ }^{73}$ Aguirre, Benigno E. 2005. "Emergency Evacuations, Panic, and Social Psychology: Commentary on 'Understanding Mass Panic and Other Collective Responses to Threat and Disaster.'" Article \#402. Newark, DE: University of Delaware, Disaster Research Center.

${ }^{74}$ Mileti, Dennis S. and Colleen Fitzpatrick. 1992. "Causal Sequence of Risk Communication in the Parkfield Earthquake Prediction Experiment." Risk Analysis 12 (3): 393-400.

${ }^{75}$ Quarantelli, E. L. 1990. "The Warning Process and Evacuation Behavior: The Research Evidence." Newark, DE: Disaster Research Center, University of Delaware.

${ }^{76}$ Drabek, Thomas E. 1968. "Disaster in Aisle 13." College of Administrative Science, Columbus, OH: Ohio State University.

${ }^{77}$ Mileti, Dennis S. and Paul W. O'Brien. 1993. "Public Response to Aftershock Warnings." Geological Survey, U.S. Department of the Interior, Washington, D.C.

${ }^{78}$ Canter, David. 1980. Fires and Human Behaviour. New York, NY: John Wiley \& Sons.

${ }^{79}$ Proulx, Guylene. 2001. "As of 2000, what do we know about occupant behaviour in fire?" Pp. 127-129 in The Technical Basis for Performance Based Fire Regulations, United Engineering Foundation Conference.

${ }^{80}$ Nigg, Joanne M. 1987. "Communication and Behavior: Organizational and Individual Response to Warnings." Pp. 103-117 in Sociology of Disasters, edited by R. R. Dynes, B. DeMarchi, and C. Pelanda. Milan, Italy: Franco Angeli Libri.

${ }^{81}$ Perry, Ronald W., Marjorie R. Greene, and Alvin Mushkatel. 1983. "American Minority Citizens in Disaster." Seattle, WA: Battelle Human Affairs Research Center.

${ }^{82}$ Perry, Ronald W. 1981. "Citizen Evacuation in Response to Nuclear and Non-Nuclear Threats." Seattle, WA: Battelle Human Affairs Research Center.

${ }^{83}$ Perry, Ronald W. and Marjorie R. Greene. 1983. Citizen Response to Volcanic Eruptions: The Case of Mt. St. Helens. New York, NY: Irvington Publishers.

${ }^{84}$ Mileti, Dennis S. and Joanne DeRouen Darlington. 1997. "The Role of Searching in Shaping Reactions to Earthquake Risk Information." Social Problems 44:89-103.

${ }^{85}$ Purser, D. A. 1985. "Human Behavior - Physiological Effects in Real Fires.” Pp. 155-162 in Interflam '85, edited by W. D. Woolley and S. P. Rogers. London, England: Interscience Communications, Inc.

${ }^{86}$ Jin, T. 1982. "Studies on Decrease of Thinking Power and Memory in Fire Smoke." Bulletin of Japanese Association of Fire Science and Engineering 32:43-47.

${ }^{87}$ Jin, T. 1981. "Studies of Emotional Instability in Smoke from Fires." Journal of Fire and Flammability 12:130142.

${ }^{88}$ Fothergill, Alice. 1998. "The Neglect of Gender in Disaster Work: An Overview of the Literature." Pp.11-25 in The Gendered Terrain of Disaster Through Women's Eyes, edited by E. Enarson and B.H. Morrow. Westport, CT: Praeger Publishers.

${ }^{89}$ Sime, Jonathan D. 1986. "Perceived Time Available: The Margin of Safety in Fires." Pp. 561-570 in Fire Safety Science -- Proceedings of the First International Symposium, edited by C. Grant and P. Pagni. London, England: Interscience Communications Ltd. 
${ }^{90}$ Sime, Jonathan D. 1983. “Affiliative Behaviour During Escape to Building Exits.” Journal of Environmental Psychology 3:21-41.

${ }^{91}$ Wiegman, Oene, Egli Komilis, Bernard Cadet, Henk Boer, and Jan M. Gutteling. 1992. "The Response of Local Residents to a Chemical Hazard Warning: Prediction of Behavioral Intentions in Greece, France and the Netherlands." International Journal of Mass Emergencies and Disasters 10:499-515.

${ }^{92}$ Connell, Rory. 2001. "Collective Behavior in the September 11, 2001 Evacuation of the World Trade Center." Preliminary Paper \#313. Newark: DE: University of Delaware Disaster Research Center.

${ }^{93}$ Aguirre, B. 1991. "Evacuation in Cancun During Hurricane Gilbert." International Journal of Mass Emergencies and Disasters 9 (1):31-45.

${ }^{94}$ Mileti, Dennis S., JoAnne DeRouen Darlington, Colleen Fitzpatrick, and Paul W. O'Brien. 1993. "Communicating Earthquake Risk: Societal Response to Revised Probabilities in the Bay Area." Fort Collins, CO: Hazards Assessment Laboratory, Department of Sociology, Colorado State University.

${ }^{95}$ Mileti, Dennis S. and Joanne DeRouen Darlington. 1997. "The Role of Searching in Shaping Reactions to Earthquake Risk Information." Social Problems 44:89-103.

${ }^{96}$ Mileti, Dennis S. and Colleen Fitzpatrick. 1993. Great Earthquake Experiment: Risk Communication and Public Action. Boulder, CO: Westview Press.

${ }^{97}$ Brennan, Patricia. 1995. "Smoke Gets in Your Eyes: The effect of cue perception on behaviour in smoke." Pp. 187-197 in ASIAFLAM '95. International Conference on Fire Science and Engineering $1^{\text {st }}$ Proceedings. London, England: Interscience Communications Ltd. 

